\title{
Anthropometry of Morocco Patients with Diabetes Type 2: Prevalence of General and Abdominal Obesity by Gender
}

\author{
Fatima Zahra Laamiri ${ }^{1,2}$, Hassan Agunaou $^{3}$ and Amina Barkat ${ }^{1 *}$ \\ ${ }^{1}$ Research Team in Maternal and Child Health and Nutrition, University Mohammed V souissi,Morocco \\ ${ }^{2}$ Higher Institute of Nursing Professions and TechnicalHealth, Morocco \\ ${ }^{3}$ Mixed Research Unit in Nutrition and Food URAC 39, (University Ibn Tufail-CNESTEN) Designated Regional Center of Nutrition Associate AFRA/ \\ IAEA,Morocco
}

Submission: June 13, 2018; Published: October 04, 2018

*Corresponding author: Amina Barkat, Équipe de recherche en santé et nutrition du couple mèreenfant, Faculté de médecine et de pharmacie de rabat,Université Mohammed V Rabat,Chef de service demédecine et réanimation néonatale. PédiatrieV.HER.chis ibn sina,

Email: Barakatamina@hotmail.fr

\section{Introduction}

The increasing incidence of obesity and types 2diabetes (DT2) is a critical public health problem [1].(NCD-RisC /AWG, 2016)given its importance as a cause of mortality, morbidity and the costs of the health system worldwide [2,3].DT 2 which was a disease diagnosed most often at an age which is close to 65 years old, is now a pathology that affects all age groups.Morocco, with regard to the countries in transition in epidemiology, is not exempt from this global trend; about 1.5 million Moroccans aged more than 20 years are diabetics [4]. The National Survey noted that the prevalence of diabetes varies from one region to another [5].According to the same source, the region of RabatsaléZemmour-Zaer, due to its geographical location and other specific characteristics, has major constraints such as high concentration of the population in the urban environment, a tendency to depopulate the countryside and, illiteracy which spares no age group of the population aged 10 years and over.. In this study we will first examine the prevalence of obesity in adults with type 2 diabetes and secondly identify the gender group that present an increased risk of obesity.

\section{Material and Methods}

This is a cross-sectional and a descriptive study, conducted between June 2016 and September 2016 at the SidiLahcenTemara Provincial Hospital in Morocco including all patients with type 2 diabetes over the age of 18 and excluding gestational diabetes and type 1 diabetes. Data collection was based on the administration of the questionnaire and anthropometric measurements. The questionnaire was designed to obtain detailed information on socio-demographic, socioeconomic and diabetes data. In addition, we measured the weight, height, waist circumference (WC) and hip circumference (HC) for each patient. These indices make it possible to assess general obesity defined for a $\mathrm{BMI} \geq 30 \mathrm{Kg} / \mathrm{m} 2$ (WHO, 1999) and abdominal obesity defined for a waist / hip ratio (WHR) high than 0.8 in women and 1 in men, and for a WC $\geq 102 \mathrm{~cm}$ in men and $\geq 88 \mathrm{~cm}$ in women (Lean et al. 1995).The IBM SPSS Statistics version 21 software was used for data analysis. The comparison of quantitative variables with normal distribution was carried out by the student $\mathrm{t}$ test or by the Mann-Whitney test when the parametric hypotheses were not satisfied. Qualitative variables were also compared using the Chi-Square or Fisher test. A threshold value of significance p of 0.05 was adopted for all statistical analyzes.The administration of theHospital of Temara prefecture SidiLahcen gave theiragreement for the realization of this study forepidemiological purposes. Informed consent wasobtained from each patientat the beginning of the study.

\section{Results}

A total of 344 type 2 diabetic patients were included in this study with a median age of 56 [50-61] and a sex ratio of 0.32 . The analysis of socio-demographic and economic parameters revealed a preponderance of the age group 50 to 59 years significantly high in men compared to women $(\mathrm{p}<0.001)$. The majority of patients were from urban areas (84.9\%), illiterate $(73.3 \%)$ and with low socio-economic in $65.1 \%$ of cases. These last two parameters were significantly elevated in women compared to men (Table 1). With regard to anthropometric parameters, the overall analysis revealed that the average values of body mass index, waist circumference and hip size ratio exceeded the overweight threshold, respectively (27.32 \pm $4.43 ; 104.36 \pm 14.78$ and $0.93 \pm 0.086$ ). The study of the global 


\section{Current Research in Diabetes \& Obesity Journal}

distribution of anthropometric variables by sex in our diabetic patients revealed that, the prevalence of obesity (86\% versus $14 \%, \mathrm{p}<0.001)$ and abdominal obesity $(84.6 \%$ versus $57.1 \%$, p <0.001), mean hip circumferences ( $p=0.036)$ and waist circumference ratio $(\mathrm{p}<0.001)$ were significantly higher in women compared to men(Table 1).

Table 1: Parameters related to socio demographic,economic and anthropometric in the overall population and in gender groups.

\begin{tabular}{|c|c|c|c|c|}
\hline \multirow{2}{*}{ Characteristics } & \multirow{2}{*}{ Global Analysis N=344 } & \multicolumn{2}{|c|}{ Bivariate Analysis } & \multirow{2}{*}{$p$} \\
\hline & & Men $n=84(24.4)$ & Women $n=260(75.6)$ & \\
\hline \multicolumn{5}{|c|}{ Socio demographic and socio-economic data } \\
\hline Age $\alpha$ & $56[50-61]$ & $58[54-68]$ & $55[47-60]$ & $<0.001$ \\
\hline \multicolumn{5}{|l|}{ AgeGroup $\beta$} \\
\hline 20 to $<30$ & $6(1.7)$ & $0(0)$ & $6(2.3)$ & \multirow{6}{*}{$<0.001$} \\
\hline 30 to $<40$ & $22(6.4)$ & $4(4.8)$ & $18(6.9)$ & \\
\hline 40 to $<50$ & $56(16.3)$ & $2(2.4)$ & $54(20.8)$ & \\
\hline 50 to $<60$ & $136(39.5)$ & $42(50)$ & $94(36.2)$ & \\
\hline 60 to $<70$ & $84(24.4)$ & $18(21.4)$ & $66(25.4)$ & \\
\hline 70 and over & $40(11.6)$ & $18(21.4)$ & $22(8.5)$ & \\
\hline \multicolumn{5}{|l|}{ Place of Residence $\beta$} \\
\hline Urban & $292(84.9)$ & $80(95.2)$ & $212(81.5)$ & \multirow{2}{*}{0.002} \\
\hline Periurban & $52(15.1)$ & $4(4.8)$ & $48(18.5)$ & \\
\hline \multicolumn{5}{|l|}{ Educational Levels $\beta$} \\
\hline Illiterate & $252(73.3)$ & $48(57.1)$ & $204(78.5)$ & \multirow{4}{*}{0.001} \\
\hline Primary & $80(23.3)$ & $32(38.1)$ & $48(18.5)$ & \\
\hline Secondary & $12(3.5)$ & $4(4.8)$ & $8(3.1)$ & \\
\hline University & $0(0)$ & $0(0)$ & $0(0)$ & \\
\hline \multicolumn{5}{|l|}{ Profession $\beta$} \\
\hline Unemployed & $72(20.9)$ & $48(57.1)$ & $24(9.2)$ & \multirow{4}{*}{$<0.001$} \\
\hline Regular work or retired & $40(11.6)$ & $22(26.2)$ & $18(6.9)$ & \\
\hline Irregular work & $24(7)$ & $14(16.7)$ & $10(3.8)$ & \\
\hline House wife & $208(60.5)$ & $0(0)$ & $208(80)$ & \\
\hline \multicolumn{5}{|l|}{ Economic Status } \\
\hline Low & $224(65.1)$ & $46(54.8)$ & $178(68.5)$ & \multirow{3}{*}{0.022} \\
\hline Intermediate & $120(34.9)$ & $38(45.2)$ & $82(31.5)$ & \\
\hline High & $0(0)$ & $0(0)$ & $0(0)$ & \\
\hline \multicolumn{5}{|l|}{ Anthropometric Variablesy } \\
\hline Weight (Kg) & $73.84 \pm 12.27$ & $75.36 \pm 10.48$ & $73,35 \pm 12.78$ & 0.194 \\
\hline Height $(\mathrm{cm})$ & $164.53 \pm 8.42$ & $170.6 \pm 7.89$ & $162.57 \pm 7.63$ & $<0.001$ \\
\hline $\mathrm{BMI}\left(\mathrm{Kg} / \mathrm{m}^{2}\right)$ & $27.32 \pm 4.43$ & $25.90 \pm 3.44$ & $27.83 \pm 4.62$ & $<0.001$ \\
\hline Waist Circumference $(\mathrm{cm})$ & $104.36 \pm 14.78$ & $104.42 \pm 13.12$ & $104.35 \pm 15.30$ & 0.966 \\
\hline Hip Circumference (cm) & $112.11 \pm 15.52$ & $109.28 \pm 13.44$ & $113.03 \pm 16.06$ & 0.036 \\
\hline Waist-to-hip ratio & $0.93 \pm 0.086$ & $0.95 \pm 0.05$ & $0.92 \pm 0.09$ & 0.008 \\
\hline BMI Group $\beta$ & & $<0.001$ & & \\
\hline Low & $2(0.6)$ & $0(0)$ & $2(0.8)$ & \multirow{4}{*}{$<0.001$} \\
\hline Moderate & $104(30.2)$ & $40(47.6)$ & $64(24.6)$ & \\
\hline Overweight & $152(44.2)$ & $32(38.1)$ & $120(46.2)$ & \\
\hline Obese & $86(25.0)$ & $12(14.3)$ & $74(28.5)$ & \\
\hline \multicolumn{5}{|l|}{ Abdominal Obesity $\beta$} \\
\hline No & $76(22.1)$ & $36(42.9)$ & $40(15.4)$ & \multirow{2}{*}{$<0.001$} \\
\hline Yes & $268(77.9)$ & $48(57.1)$ & $220(84.6)$ & \\
\hline
\end{tabular}


Notes: Values are expressed as médiane and interquartils $(\alpha)$, count and percentage $(\beta)$ or mean and standart deviation ( $(\mathrm{\gamma})$. For body mass index (BMI) groups: low $\mathrm{BMI}=<, 18.5 \mathrm{~kg} / \mathrm{m}^{2}$; normal $\mathrm{BMI}=18.5$ to $<25 \mathrm{~kg} / \mathrm{m}^{2}$; overweight $\mathrm{BMI}=25$ to $<30 \mathrm{~kg} / \mathrm{m}^{2}$; obese $\mathrm{BMI}=>30 \mathrm{~kg} / \mathrm{m}^{2}$. Obesity was defined for waist circumference $\geq 102 \mathrm{~cm}$ for men and $\geq 88 \mathrm{~cm}$ for women. Significance threshold $\mathrm{P}<0.05$.

*These results were statistically significant.

\section{Discussion}

344 patients with DT2 were recruited as part of their biological assessment in the laboratory of the hospital of SidiLahcen in the city of Temara. At the end of our study, we found that the most affected age group by DT2 was 50 to 59 years. These findings are in line with the latest national estimates, which have reported a prevalence of more than $14 \%$ in age groups beyond 50 years compared to a prevalence of $9 \%$ among all those aged over 20 years. We also found that threequarters of diabetic patients were women (75.6\%).This finding are supported by several studies which revealed that type 2 diabetes is a predominant pathology in women [6,7], in addition the National Family Health Survey [4] advocate that a women constitute a risk group. Regarding the analysis of anthropometric parameters, our work has highlighted a significantly higher increase in general and abdominal obesity in women compared to men. The analysis of trends in diabetes in Africa has shown that the age-standardized mean BMI increased from $21.0 \mathrm{~kg} / \mathrm{m} 2$ (95\% credible interval: $20.3-21.7)$ to $23.0 \mathrm{~kg} / \mathrm{m} 2(22.7-23.3)$ in men, and from $21.9 \mathrm{~kg} / \mathrm{m} 2$ (21.3-22.5) to $24.9 \mathrm{~kg} / \mathrm{m} 2(24.6-$ 25.1 ) in women and the age standardized prevalence of diabetes increased from $3.4 \%(1.5-6.3)$ to $8.5 \%(6.5-10.8)$ in men, and from $4.1 \%(2.0-7.5)$ to $8.9 \%(6.9-11.2)$ in women[8].Taking into account the findings of this study we can make a link with the results of this work showing a preponderance of obesity and diabetes in female diabetic patients.

\section{Conclusion}

This work may provide the best opportunity to promote a healthy lifestyle including obesity prevention particularly in women who present an important risk of DT2.

\section{References}

1. NCD Risk factor Collaboration (NCD-RisC) (2016) Worldwide trends in diabetes since 1980 : a pooled analysis of 751 population-based studies with 4.4 million participants. Lancet 387(10027) : 1513-1530.

2. The Global Burden of Metabolic Risk Factors for Chronic Diseases Collaboration (BMI Mediated Effects), Lu Y, Hajifathalian K, Ezzati M, Woodward M, et al. (2014) Metabolic mediators of the effects of bodymass index, overweight, and obesity on coronary heart disease and stroke: a pooled analysis of 97 prospective cohorts with 1.8 million participants. Lancet 383(9921): 970-983.

3. The Global Burden of Metabolic Risk Factors for Chronic Diseases Collaboration (2014) Cardiovascular disease, chronic kidney disease, and diabetes mortality burden of cardiometabolic risk factors from 1980 to 2010: a comparative risk assessment. Lancet Diabetes Endocrinol 2(8): 634-647.

4. National Survey on Population and Family Health (2011) Ministère de la santé, Direction de la planification et des ressources financières, Division de la planification et des études, Service des études et de l'information sanitaire. Enquête nationale sur la population et la santé familiale 2011-Indicateurs régionaux.

5. National Survey on Population and Family Health (2012) Ministère de la santé, Direction de la planification et des ressources financières. Division de la planification et des études et service des études et de l'information sanitaire. Enquête Nationale sur la Population et la Santé Familiale (ENPSF).

6. Tull E, Roseman J (1995) Diabetes in African Americans. In: Diabetes in America (2 ${ }^{\text {nd }}$ edn), NIH Publications, Bethesda, USA, pp: 613-630.

7. Sobers-Grannum N, Murphy MM, Nielsen A, Guell C, Samuels TA, et al. (2015) Female gender is a social determinant of diabetes in the caribbean: a systematic review and meta-analysis. Plos One 10(5): 0126799.

8. NCD Risk Factor Collaboration (NCD-RisC) - Africa Working Group (2017) Trends in obesity and diabetes across Africa from 1980 to 2014: an analysis of pooled population-based studies. Int J Epidemiol 46(5): 1421-1432.
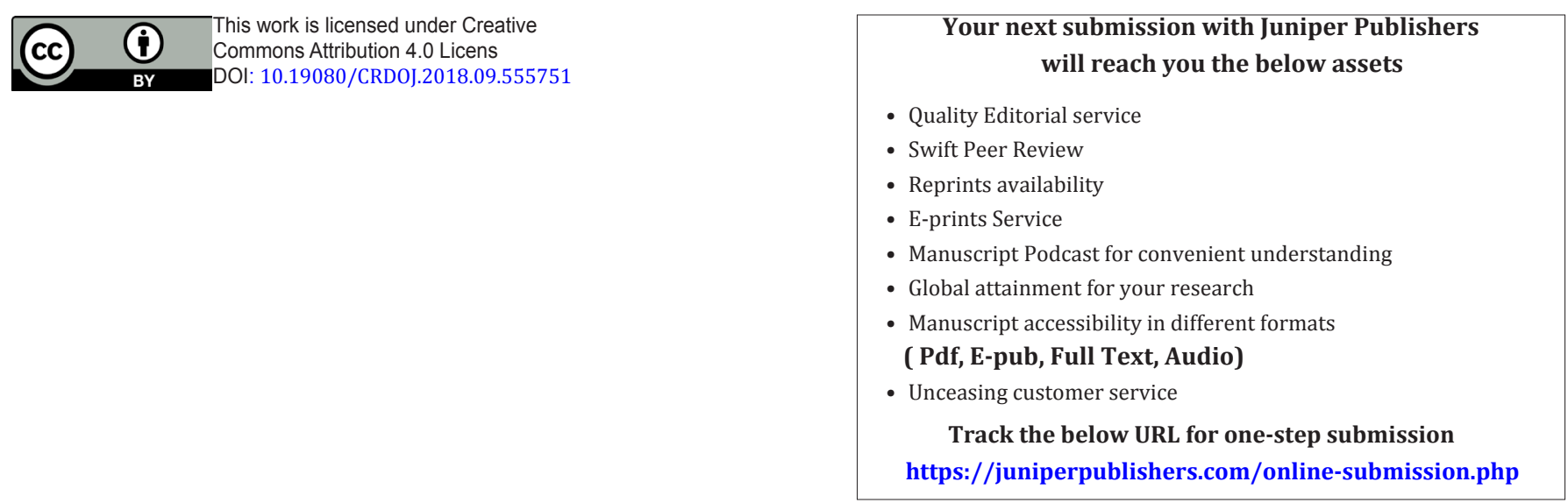